\title{
IDŐJÁRÁS
}

Quarterly Journal of the Hungarian Meteorological Service

Vol. 125, No. 3, July-September, 2021, pp. 397-418

\section{Validation of subgrid scale ensemble precipitation forecasts based on the ECMWF's ecPoint Rainfall project}

\author{
Boglárka Tóth and István Ihász* \\ Hungarian Meteorological Service, \\ P.O. Box 38, H-1525 Budapest, Hungary
}

Corresponding authorE-mail: ihasz.i@met.hu

(Manuscript received in final form January 11, 2021)

\begin{abstract}
Nowadays, state-of-the-art numerical weather prediction models successfully predict the general weather characteristics several days ahead, but forecasting extreme precipitation is quite challenging even in the short time range. In the framework of the ecPoint Project, the European Centre for Medium-Range Weather Forecasts (ECMWF) developed a new innovative probabilistic post-processing tool which produces 4-day precipitation forecast as accurate as the raw ensemble forecast at day 1. In the framework of the scientific co-operation between ECMWF and the Hungarian Meteorological Service (OMSZ), we were invited to participate in the validation of the experimental products. Quasi operational post-processed products have been available since July 1, 2018. During our work, besides using different verification technics, a new ensemble meteogram was also developed which can support operational forecasters during extreme precipitation events. As a result of our work, products of the ecPoint Project have been included in the operational forecasting activity.
\end{abstract}

Key-words: extreme events, ensemble forecasts, post-processing, calibration, precipitation, probability, numerical weather prediction models, early warning, case studies, ECMWF 


\section{Introduction}

On July 1, 1994, the cooperation agreement between Hungary and ECMWF entered into force. Since then, it has proved very beneficial for a wide range of activities, including the contributions the Hungarian Meteorological Service (OMSZ) has made to several developments at ECMWF (Ihász and Modigliani, 2019). In the summer of 2018, OMSZ was invited to take part in the validation of the ecPoint Rainfall project lead by the European Centre for Medium-Range Weather Forecasts (ECMWF).

In the framework of the ecPoint Rainfall project, ECMWF has developed a probabilistic point-rainfall product which could support the prediction of flash floods across the globe (Pillosu and Hewson, 2017). The product, which is based on an innovative post-processing method, aims to bridge the gap between the relatively coarse resolution of today's global forecasting models and the higherresolution limited-area models needed to describe localized heavy rainfall. The methodology is based on physically relevant statistical relationships between the larger-scale weather features well represented by ECMWF forecasts and local realizations represented by point observations. These relationships make it possible to compute statistically based (rather than raw-ensemble-based (Mátrai and Ihász, 2017; Ihász et al., 2018)) probabilities for point rainfall. This includes extremes, which can be used to infer the likelihood of flash floods for use on platforms such as the European and Global Flood Awareness Systems (Hewson et al., 2019).

This new post-processing method blends together information from different locations whenever they experience similar rainfall generation mechanisms, assuming that these physical mechanisms are universal and dependent on key atmospheric and geographic properties (Hewson and Pillosu, 2020). This means that:

- one year of global rainfall observations is adequate, because it can equate to hundreds of years used in locally-calibrated techniques, and

- extremes can be successfully predicted, even when they do not exist in a local record.

Moreover, the reliance on physics means that forecasts can be confidently produced for anywhere in the world, even places without observations. The post-processing system has been fully automated and requires minimal computing resources to run compared to high-resolution numerical models (Hewson and Pillosu, 2021).

One of the most important benefits of this innovation is that it does not need long timeseries as most of the post-processing technics required in the last several decades. During post-processing which required long timeseries, reforecast dataset was needed due to regular model developments, but in the other hand the lack of the continuous high quality observation is a typical and 
unsolved problem. Post processing technics based on ECMWF model using reforecasts could not be a problem as 20 years of reforecasts are operationally available, but comprehensive observation precipitation datasets can be a serious problem in Europe, including Hungary too, because extreme precipitation is typically concentrated on a very small region.

\section{Former developments aiming to improve precipitation forecasts}

\subsection{Using numerical model products at the eighties}

Necessity of the study of meteorological and hydrological circumstances of floods on two main rivers (Danube and Tisza) got a special emphasize after a severe flood event on Tisza, which caused extreme damages in spring 1970 (Bonta and Ujváry, 2011). In the middle of the 1970s, several projects were realized to study the weather scenarios causing heavy floods. As model forecasts from large European meteorological services were available only in the beginning of the $1980 \mathrm{~s}$, a statistical method was constructed to estimate the precipitation amount (Bodolainé, 1983).

Since the '70s, at the largest meteorological services global models have been operationally running, and relatively few countries were able to run regional models providing downscaled weather forecasts. In the ' $80 \mathrm{~s}$, due to the rapid development of limited area regional models, significant benefits could be provided especially in surface weather parameters, like precipitation, $10 \mathrm{~m}$ wind, and $2 \mathrm{~m}$ temperature compared to global forecasts. Consequently, the Hungarian Meteorological Service (OMSZ) considered to implement a state-of-the-art model in the second part of the 1980 s,

\subsection{Using limited area models since early nighties}

At the end of the 1980s, the use of limited-area models (LAMs) became a key element in operational weather forecasting in some European countries. At the time, the Swedish grid point LAM was one of the best, specially precipitation forecasts were quite good comparing to other models. OMSZ acquired it in 1988. Dezső Dévényi headed a small new team focusing on this activity. Having solved several problems, in July 1991, a version of the model with a horizontal resolution of $0.9^{\circ} \times 0.9^{\circ}$ covering Europe and 12 levels in the vertical became operational at OMSZ (Ihász, 1992). At that time, it was not possible to obtain adequate lateral boundary conditions from the Global Telecommunication System (GTS). There was an obvious solution to this problem: to use ECMWF data as lateral boundary conditions. 
Among one of his first activities, Iván Mersich, the new president of OMSZ, sent an application by the Hungarian Meteorological Service to join ECMWF as a member (Woods, 2005). In the event, a cooperation agreement between ECMWF and Hungary was signed in the spring of 1994 (Kaba, 1994). Lateral boundary conditions then became available and were used operationally in the LAM model. This development led to significantly improved forecast quality for the rest of the life of this LAM, until 1998 (Ihász, 2014).

Hungary was one of the first countries to participate in the ALADIN project led by Météo-France since 1991 (Horányi et al., 1996; Horányi et al., 2006). In 1998, the ALADIN/HU model became operational at OMSZ, on a new high-performance computing facility. In the first ten years of operations, the model was coupled to the global ARPEGE model. It was then coupled to ECMWF's deterministic global model, resulting in significant improvements in the quality of the forecasts provided by OMSZ (Bölöni et al., 2009).

Since 2009, OMSZ has been running the ALADIN model with 11 ensemble members (Horányi et al., 2011). In 2016, ECMWF started to provide ensemble lateral boundary conditions in the framework of the Boundary Condition (BC) Optional Programme. OMSZ has been using them ever since, thus improving the quality of its probabilistic forecasts (Szücs et al., 2016).

In the first decade of this century, the AROME non-hydrostatic model was developed in the framework of international cooperation. In 2010, the AROME model was made operational at OMSZ (Mile et al., 2015; Szintai et al., 2015). This non-hydrostatic model provides very useful information, especially on extreme precipitation events in summer.

\subsection{Ensemble product development}

Over the last 25 years, OMSZ has worked in various areas of product development. They include many pioneering activities in the use of ensemble forecasts, a special attention was paid to improve quality of the precipitation forecasts. Since 2003, ensemble clustering focusing on Central European meteorological patterns has been run operationally using resources provided by ECMWF's ecgate computing cluster (Ihász, 2004). This system makes available the representative ensemble member and the ensemble mean for each cluster to the General Directorate of Water Management. OMSZ has also been able to significantly improve the quality of the ensemble forecasts by means of calibration for variables such as 2-meter temperature, 10-meter wind speed, and precipitation (Ihász et al., 2010; Mátrai and Ihász, 2017; Ihász et al., 2018).

Since 2011, OMSZ has developed ensemble vertical profiles (Ihász and Tajti, 2011). These can support decision-making for precipitation type in winter and for the intensity of convective events in summer. In 2018, ECMWF developed a similar method for the ecCharts visualization system. 
The version of ECMWF's Integrated Forecasting System introduced operationally in May 2015 (IFS Cycle 41r1) contained precipitation type as a new experimental product (Forbes et al., 2015). At OMSZ, an ensemble precipitation type diagram was developed in autumn 2015 supporting the forecasters' decision making during the winter season. A similar ECMWF product was created in the framework of the EU-funded ANYWHERE project inspired by the bar chart product from OMSZ, exploiting the probabilistic information provided by ECMWF ensemble forecasts (Gascon et al,, 2018).

\section{Study of the subgrid scale ensemble precipitation forecast based on the ecPoint Rainfall project}

Forecasts of the precipitation amount and intensity are the most important challenges for the meteorologists; furthermore, the correct estimates are not negligible from the perspective of the society. Nowadays, when extreme storms are becoming common, one of the most relevant tasks is the most accurate prediction of convective rainfall. To make such predictions, forecasters use numerical model outputs, which often over- or underpredict the real measurements. Naturally, the resolution of the models significantly contribute to these inaccuracies, so the high resolution non-hydrostatic models, which describe the vertical upflow in an explicit way, give assistance to the convective predictions. Taking into account this information, there are excessive expectations of the local, extreme precipitation forecast, mostly in areas with complex orography, because the subgrid variability is difficult to represent.

The problem is exacerbated by the appearance of extreme weather conditions, which occur in significant numbers annually in Hungary. In such extreme situations, over a short period of time, huge precipitation is registered locally, which often results in flash flood events. A number of stations do not prepare for such suddenly forthcoming disasters, hence vast damages can happen in a few hours. Currently, the forecasters alarm for these situations by using the output of the high-resolution nonhydrostatic limited-area model and radar nowcasting on ultra-short range. This solution also holds some difficulties; for example, the warning lead time is reduced to only a few hours. At OMSZ, forecasters make warning up to four days. These warnings are based typically on ECMWF's high resolution and ensemble models.

To eliminate these problems, ECMWF developed a new post-processing method within the framework of the project ecPoint Rainfall (Hewson and Pillosu, 2020) between 2015 and 2018, that could support the more accurate prediction of extreme local precipitation across the globe. The new postprocessed rainfall forecast is also called ecPoint Rainfall, which is a probabilistic product based on the ensemble forecasts. 


\subsection{The ecPoint Rainfall project lead by ECMWF}

The new post-processing method developed by ECMWF usually warns about heavy rainfall earlier and more precisely than previous forecast systems. This ability plays a particularly important role in the estimation of flash flood events, which are one of the most devastating hazards, especially in mountainous areas. As ecPoint Rainfall is a global product, for the research it was worth to select partner countries from different climatic areas to see if the method performed similarly well in different locations. Only four countries joined the project, thus it was an outstanding honor that beside Costa Rica, Ecuador, and Peru, the Hungarian Meteorological Service could participate in the ecPoint Rainfall research as well, representing the areas of continental climate. With the accession, OMSZ gained a number of advantages - as opposed to non-participating countries -, including the GRIB files have been received from ECMWF and have been archived, which allowed this study to be completed.

The aim of ecPoint Rainfall is to offer some information on the probability of precipitation in the sub-grid area, because most users would like to know the expected weather at a specific location instead of an average value per gridbox (Owens and Hewson, 2018). The calibration of ensemble forecasts are taken as a basis in the method, which uses 5 different meteorological parameters (convective fraction, total precipitation, $700 \mathrm{hPa}$ wind, convective available potential energy (CAPE) index, and 24 hour incident clear sky solar radiation) with appropriate emphasis to produce the 99 members of ecPoint Rainfall data set. In summary, with the new methodology we can estimate the range of total precipitation in the grid box and derive the probability value of different points within the grid using different statistical methods. During the one-year-long calibration, the shortterm 12 hours rainfall forecasts were compared with synoptic observation data, and a forecasts error ratio (FER) was computed for each forecast. Since then, with proper use of FER, they have been improving the original ensemble predictions for anywhere on Earth based on an algorithm that learns the past.

\subsection{Studies based on ecPoint Rainfall forecasts}

In this study, first we examined the reliability of ecPoint Rainfall, for which Talagrand diagrams were made. Days were separately analyzed with extreme rainfall in 2018, and then they were evaluated the success of the new product using a verification algorithm. After the verifications, the new ensemble meteogram was reviewed. Last but not least, through a case study we described the benefits of the new ecPoint Rainfall product. 


\subsection{Verification}

In case of every new product, including the ecPoint Rainfall project, it is vital to gain understanding of the reliability of the results. In order for all the new information to be applied in the most appropriate way in operational activities, it is necessary to review the main advantages and sources of error of ecPoint. For this purpose, first, a verification was made of the 2018 summer period (Tóth, 2020).

In the course of this research, we took into account those synoptic observation stations in Hungary, where a 12-hour precipitation amount can be derived. Thus, we were able to work with the verified data of a total of 310 stations that the Unit of Informatics Applications of the Hungarian Meteorological Service provided for us. To display the scattered observation stations on a map, the MAGICS software was chosen (Fig. 1). The map represents an inhomogeneous distribution, which is justified by the topography of Hungary. To separate the lowland stations from the hilly stations, we used various symbols and colors. The lowest measuring points were indicated with green, while those located higher than 600 meters with black.

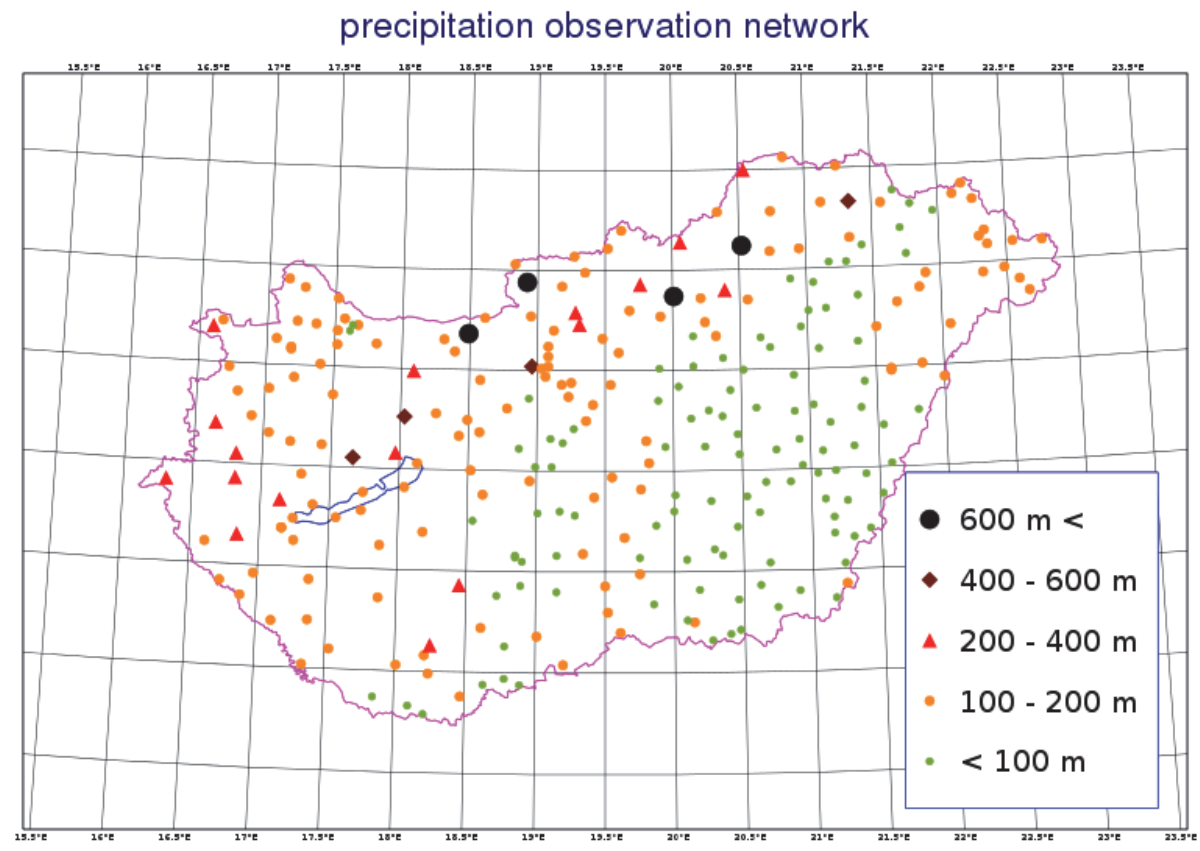

Fig. 1. Network of precipitation measurements in Hungary.

In addition to observation data, the 12 hours ecPoint Rainfall forecasts and ensemble forecasts have been used for verifications as well. All examinations 
were made for the summer of 2018. First, the Talagrand diagrams were based on the +12 hours forecasts, then the diagram pairs were extended to a higher time step, so the verification of the $+12,+36,+60,+84$ and +108 hours forecasts were also completed.

The values of the horizontal axis of the Talagrand diagram are determined by the values of the sorted probability predictions. For the 99-member ecPoint Rainfall, the $\mathrm{x}$ values are specified by nearly 2 forecast values. Thus, on the $\mathrm{x}$ axis - corresponding with the professional literature - the number of the ensemble member is displayed. The columns show the relative frequency of cases where the measured values fall between two adjacent ensemble members. A probabilistic prediction is applicable if all values can occur with nearly equal probability. As a result, if the Talagrand diagram shows a smooth, flat shape, the forecast is considered reliable. If outliers appear on either of the edges of the chart, i.e., the figure becomes $\mathrm{L}$ or $\mathrm{J}$ shaped, then the possibility of a systematic underestimation or overestimation should be taken into consideration. If this problem exists on both sides, then the measured values are mostly outside the range of probability predictions, and it becomes practical to extend the range of the ensemble.

Not all of the completed diagrams are presented as almost the same structure appeared in the figures, so for the sake of illustration, we only analyze the Talagrand diagrams made from the +12 hours (Fig. 2) and +108 hours (Fig. 3) forecasts.
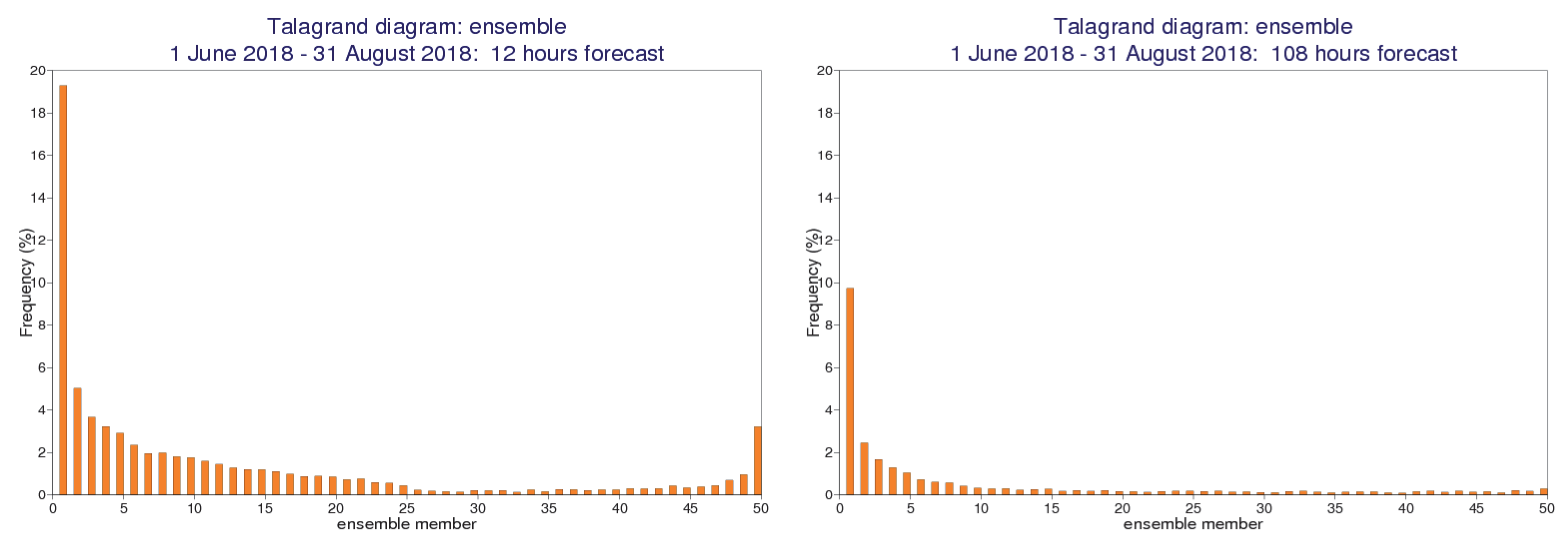

Fig 2. Talagrand diagrams of 12 hours forecast for ecPoint Rainfall (left) and ensemble foreast (right). The investigated time interval is June 1, 2018 -August 31, 2018. 

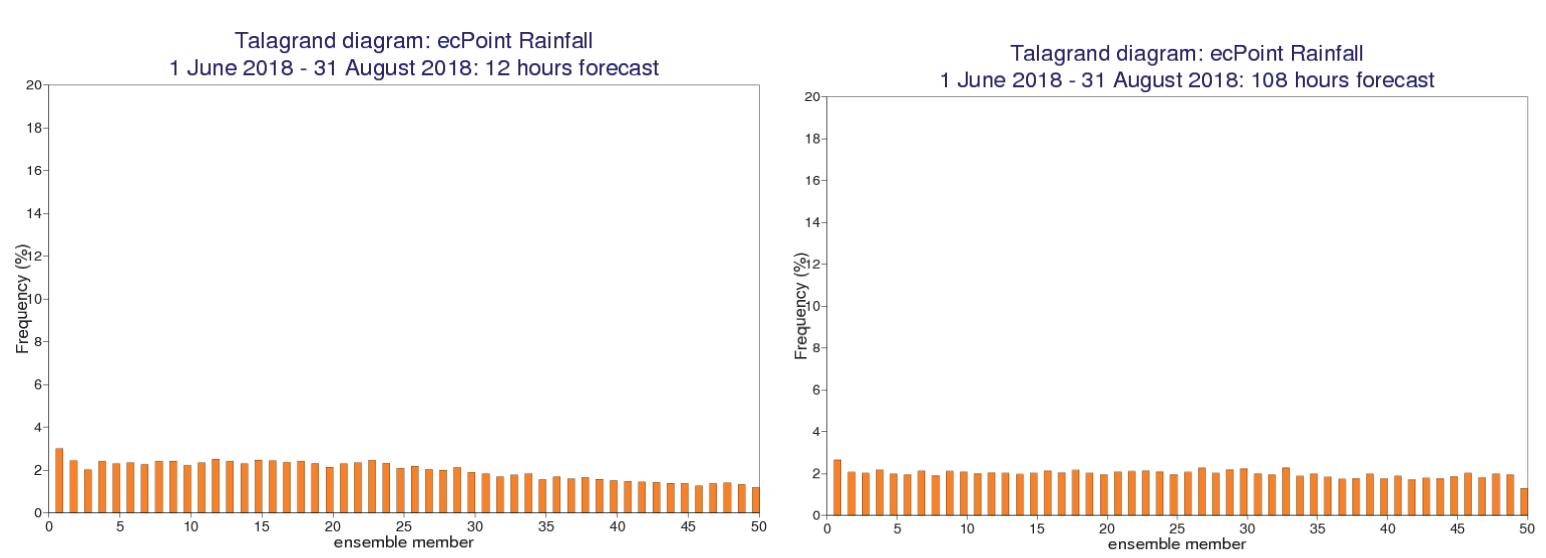

Fig. 3. Talagrand diagrams of 108 hours forecast for ecPoint Rainfall (left) and ensemble forecast (right). The investigated time interval is June 1, 2018 -August31, 2018.

Summarizing the verification diagrams, it was demonstrated that the ecPoint Rainfall forecasts proved to be much more reliable in the period we examined than the ensemble forecasts for both low and high ensemble serial numbers. In the Talagrand diagram, each value occurred with a relative frequency of $2-4 \%$, suggesting low systematic failures of ecPoint Rainfall. Meanwhile, on the ensemble Talagrand diagrams an L-shape stands out, alluding to a systematic overestimation. If we compare the chart made from the +12 hours forecasts with the +108 hours forecast, significant differences can not be determined; however, a less wavering form is outlined. As the ECMWF ensemble model targeting to provide good quality in medium range (2-10 days) ensemble precipitation forecasts have typically less wide ensemble-spread than it is needed in ultra-short range or short range scales.

After that, we have started to examine days of extreme rainfall in Hungary. We selected those days when the observed precipitations exceeded the $20 \mathrm{~mm} / 12$ hours limit from the 92 days of the summer of 2018 at any of the 310 stations examined in our research. If the precipitation anywhere in the country exceeded the predefined limit, it was already included in the extreme days. Firstly, we studied the interval from midnight to noon and we found 24 days of extreme rainfall. Then we used the same algorithm searching for extremes in the ecPoint database as well.

The ecPoint Rainfall is a post-process ensemble output that consists of 99 members, so we were looking for days in excess of $20 \mathrm{~mm}$ precipitation for different percentiles. Based on our research, we determined that the use of the 85th percentile level is one of the most optimal values, because in this case the ecPoint Rainfall warns of almost all extreme events, meaning its predictions do 
not significantly differ from reality. So when we used the 99th percentile level, we found more extreme events than in the observed database, and towards the smaller percentile levels we found fewer. (The study of extreme rainfall days was also performed for several precipitation limits.)

After filtering out the days of extreme rainfall, we displayed them on both the observation and the ecPoint Rainfall database and made subjective verifications. From the 24 extreme rainy days, we analyzed an event occurred on June 9, because several consecutive thunderstorm systems arrived in Hungary on this day. The morning thunderstorms arriving from the south concentrated between the Danube and the Tisza, where $60 \mathrm{~mm} / 12$ hours rainfall was measured (Fig. 4). At the same time, there was cloudless, sunny weather in the eastern, northeastern regions of the country.

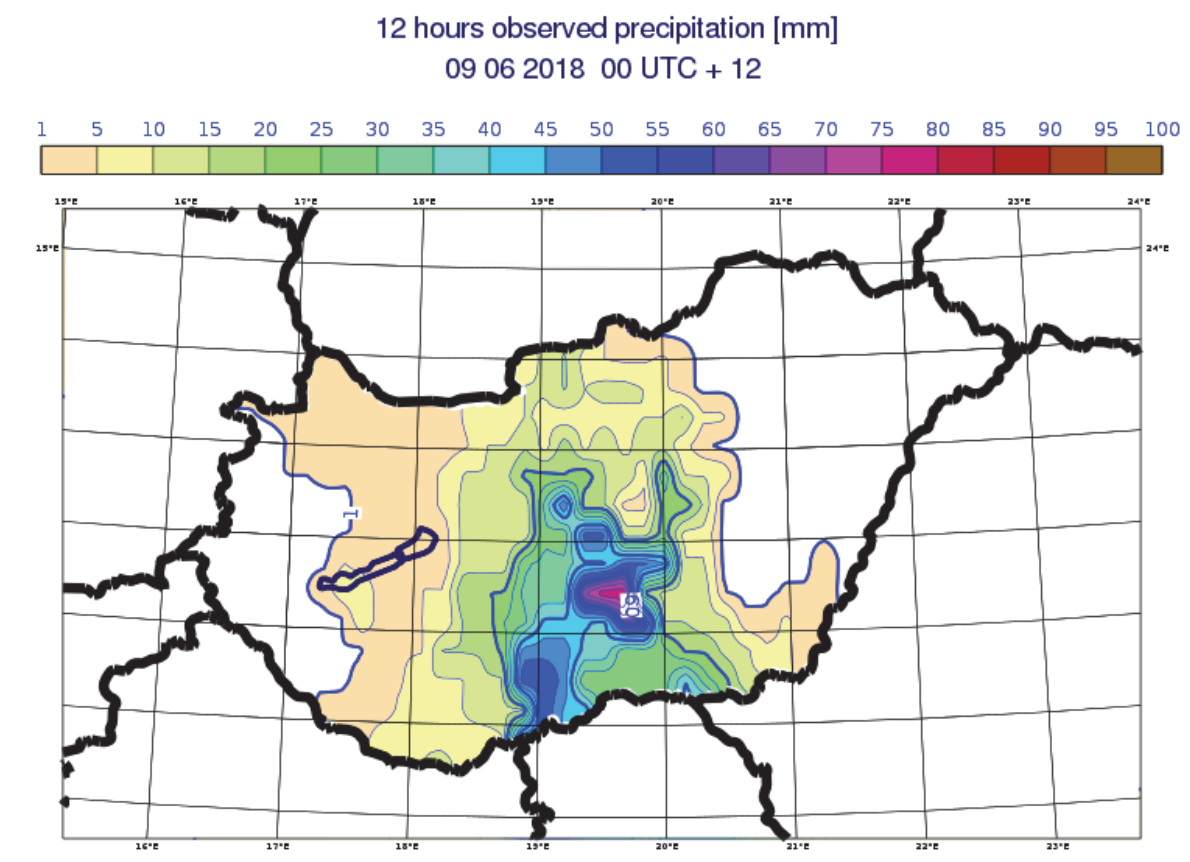

Fig 4. Observed 12h amount of precipitation at 12 UTC, June 9, 2018.

If we examine the short-term +12 hours forecasts of one of the most optimal percentiles, i.e., the 85th ecPoint Rainfall member, we can see that an intense rainfall covering a large area was expected in the central and western parts of Hungary. On the map made from ecPoint Rainfall data (Fig. 5), the rainy areas are nicely outlined, similarly to the map containing the measured values. Naturally, the model forecast designates a somewhat wider zone than was affected in reality, but in terms of its structure, it assigned the rainy and dry areas precisely. 


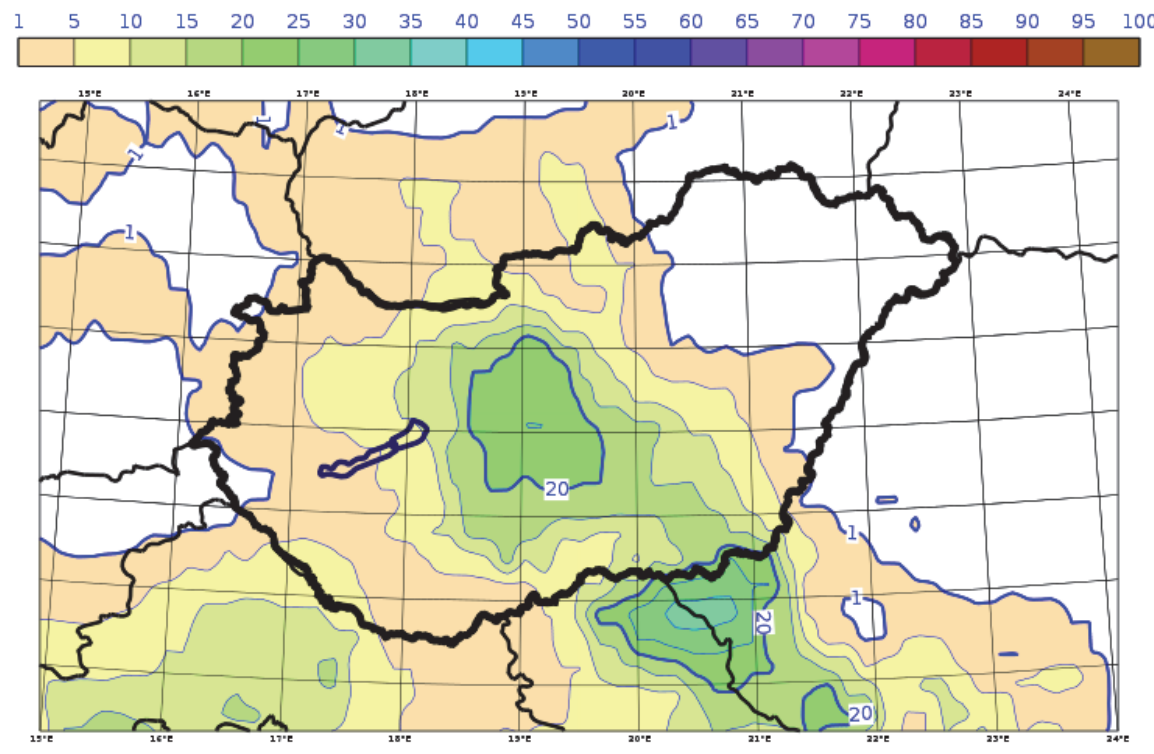

Fig. 5. $12 \mathrm{~h}$ amount of precipitation provided by the 85 th member of ecPoint Rainfall at 12 UTC, June 9, 2018.

Analyzing the 24 cases, the results showed that the position error is typically smaller over mountainous areas than over flat areas; however, ecPoint Rainfall provides more precise forecasts for frontal systems and squall lines. This can be explained by the fact that in the lowland, the orographic force does not play a significant role in the formation of thunderstorms, thus the locations of extreme precipitation become random. Even in the case of locally occurring thunderstorms, the new product provided excellent estimates of precipitation at the regional level, and its various percentiles also adequately warned of the likelihood of more extreme precipitation.

Following the visual analysis of the maps, we invented a new kind of scoring technique for the verifications, which can also illuminate the spatial accuracy of the ecPoint Rainfall. Before we started the verification study, we interpolated the observation values to a grid of ecPoint Rainfall with a spatial resolution of $0.16 \times 0.16$. During the interpolation, we fitted each measured value to the closest grid point, as long as it did not exceed a distance of $25 \mathrm{~km}$. With this solution, we tried to avoid substituting missing data areas with false values. After the interpolation, the data were available on the same grid, so the spatial accuracy had become verifiable.

The success of the forecasts had been assessed with a point system within the predefined threshold index of precipitation. If the value of the measured and the ecPoint member remained below the threshold index, we gave 0 point, if it 
exceeded it, we gave 1 point. If the two data differed in their estimation in either direction, we gave -1 point. Upon the summation of these points, we displayed them on a map using the MAGICS program. The ecPoint Rainfall performed well in areas where the figures were dominated by positive values; however, where the negative values prevailed, the forecasts were less accurate. We obtained an almost homogeneous map with a value of around 0 point. This was the first attempt to compare forecasts to observed values. The deviation between one observed grid point and one forecasted grid point was examined.

Since a forecast can be accepted even if it predicts extreme precipitation amounts a few grid points away, it has become expedient to further develop the new verification method. In the following, we did not examine a specific grid point, but a specific area. Firstly, we compared one forecasted gridpoint to 5 surrounding grid points in each direction (i.e., 11*11 grid points). The area used in the examination of the success of the forecast became an area with a diameter of almost $200 \mathrm{~km}$. On the maps made this way, we drew only values above 0 in order to provide a better illustration. As a result, we achieved much more encouraging results, because the areas with a positive score dominated across the country. Regions where ecPoint Rainfall underestimated or overestimated the measured values remained white.

As the aim of the new product is to forecast the local precipitation zones as accurately as possible, it was worth narrowing the deviation of 5-5 grid points and examining the results of ecPoint Rainfall under even stricter conditions. Under this, we compared one forecasted grid point to 3 observed grid points in each direction (i.e., $7 * 7$ grid points, approximately $50 \mathrm{~km}$ in each direction).

The results thus obtained were also quite encouraging. The maps were prepared for several ecPoint Rainfall members for different precipitation thresholds as well, of which a map representing the 85 th and 95th percentiles belonging to the $15 \mathrm{~mm}$ threshold index was presented. The ranges with a positive score were slightly narrower compared to the maps that allowed a deviation of 5-5 grid points (based on the maps for the 85th member) (Fig. 6); however, excluding the Great Plain areas, the performance of ecPoint Rainfall still dominated. 


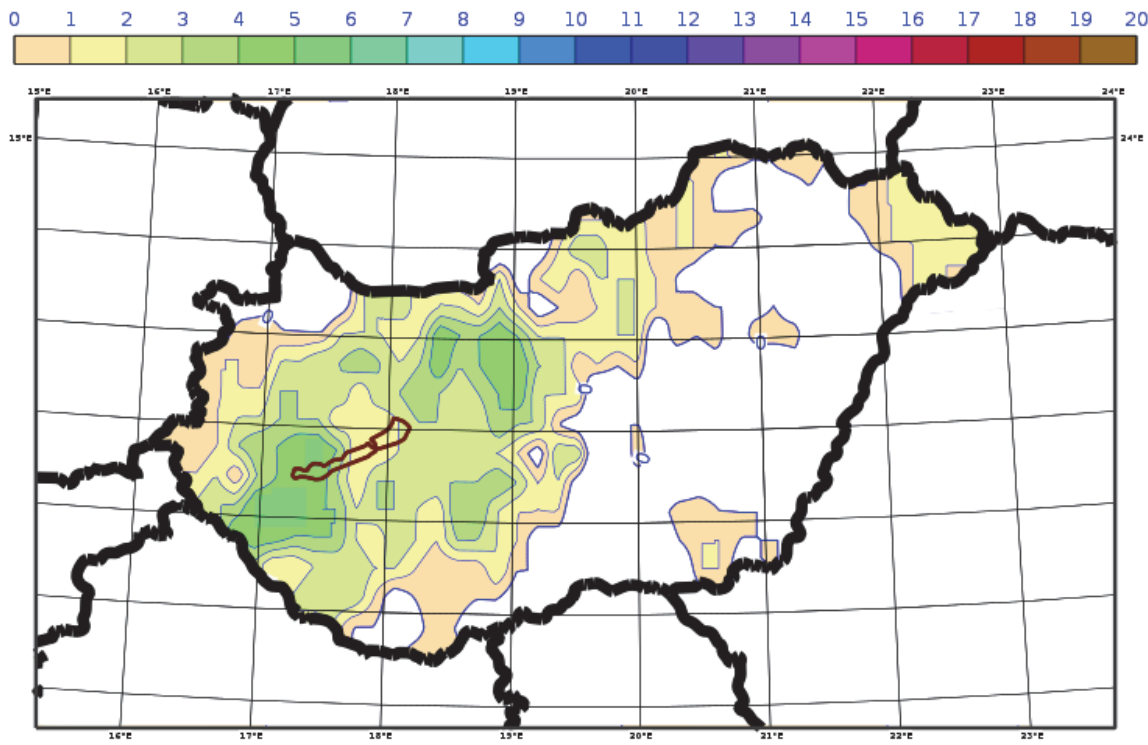

Fig. 6. Total number of events for the 85th member of ecPoint Rainfall exceeding $15 \mathrm{~mm} / \mathrm{h}$.

Because the members of ecPoint Rainfall are sorted probability members, the higher percentiles belong to higher precipitation amounts. It is no accident that higher scores appeared on the map for member 95, as there were several events when the ecPoint rainfall forecast exceeded the predefined threshold index (Fig. 7).

total number of events

ecPoint Rainfall member: 95 , limit: 15.0 mm/12 h <

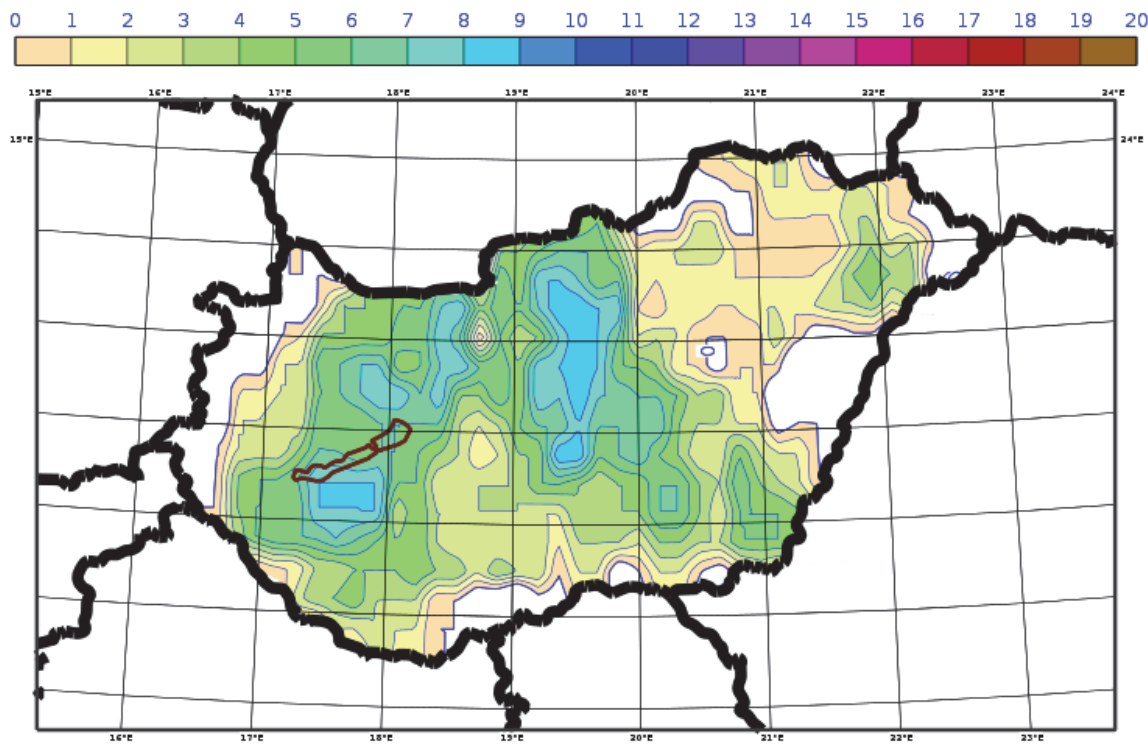

Fig 7. Total number of events for the 95th member of ecPoint Rainfall exceeding $15 \mathrm{~mm} / \mathrm{h}$. 
It is worth highlighting that the higher percentile members often overestimate the real measurement, thereby larger areas are marked with positive points. These members estimate more extreme precipitations in a wider band. To conclude, the spread of the ecPoint Rainfall probability forecast informs the forecasters from the most favorable conditions to the most extreme events. Based on the new verification method, it can also be established that the 85th member provides one of the most optimal forecasts.

In the second half of the study, we began to deal with the under- and overestimation of ecPoint Rainfall. Using an algorithm similar to the previous verification, we developed a point-based verification method to determine the extent of under- and overestimations for extreme rainy days. If the value of the measured and the ecPoint member remained below or exceeded the threshold index, we gave 0 point for the forecast. In cases where the observation values were below the selected threshold index while the ecPoint Rainfall values were above, we gave 1 point; otherwise, we gave -1 point for the given forecast. During this verification examination, we allowed 3-3 grid point deviations in each direction from the given grid point, and then we summed the scores thus calculated onto each grid point. On the map, the underestimated, negative value areas were marked blue, while the overestimated, positive areas were marked orange. Areas where neither underestimation nor overestimation occurred were illustrated in white.

In the course of this analysis, we also performed studies for several precipitation thresholds, of which we presented the maps produced from the 85th and 95th percentiles belonging to the $15 \mathrm{~mm}$ threshold index. The results in Fig. 8 unquestionably confirm the previously described result, that the 85th member of the ecPoint Rainfall provides the most accurate prediction, while the higher percentiles often overestimate the actual measured values. A significant part of the country was white on the map representing the 85th percentile, as opposed to the map displaying the 95th percentile that reflected absolute overestimation with orange dominating the map (Fig. 9). 
balance of under and overestimations : ecPoint

ecPoint Rainfall member, 85 limit: $15.0 \mathrm{~mm} / 12 \mathrm{~h}<$

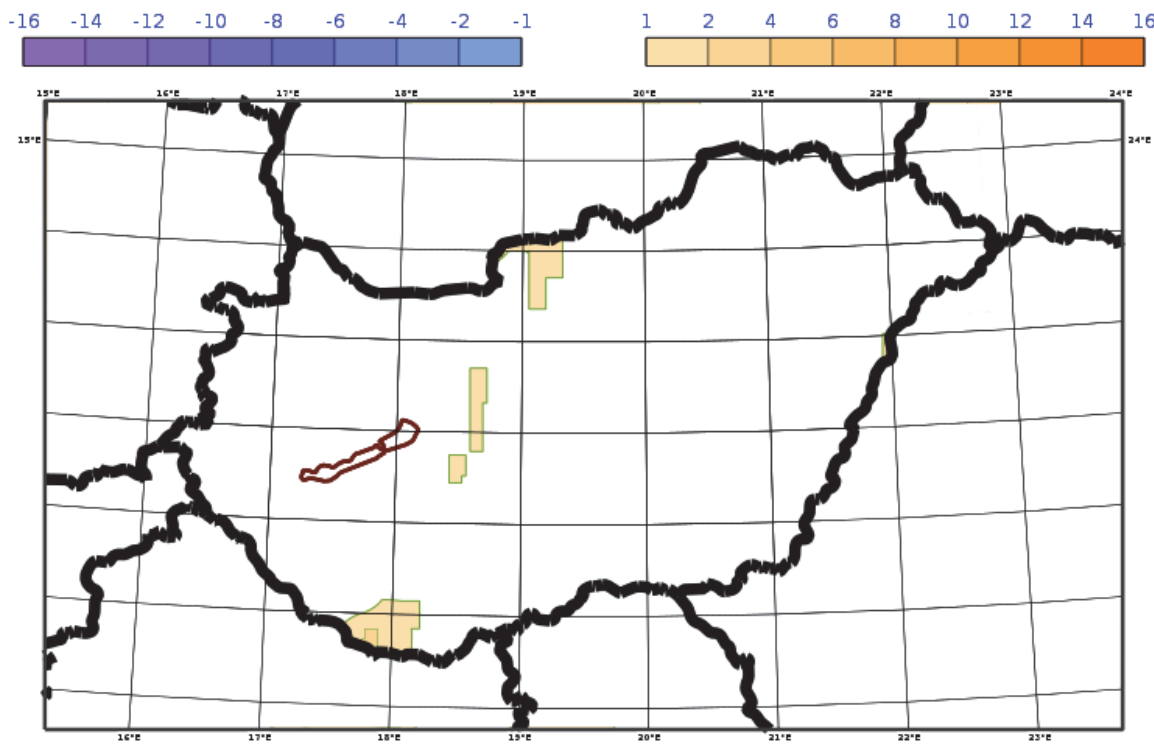

Fig. 8. Map produced from the 85 th percentiles belonging to the $15 \mathrm{~mm}$ threshold index.

balance of under and overestimations : ecPoint ecPoint Rainfall member, 95 limit: $15.0 \mathrm{~mm} / 12 \mathrm{~h}<$

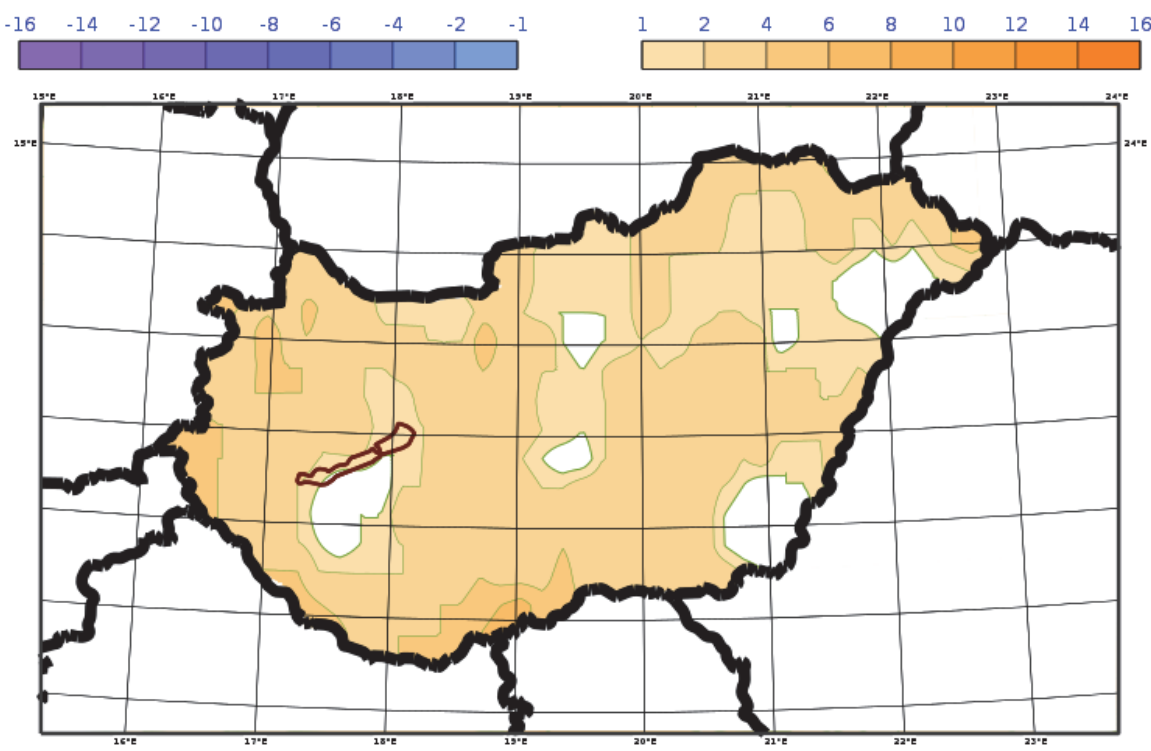

Fig. 9. Map produced from the 95th percentiles belonging to the $15 \mathrm{~mm}$ threshold index. 


\subsection{Case study}

Finally, after the verification results, we would like to highlight the main benefits of the ecPoint Rainfall product, which is the most effective in the predictions of summer, convective situations, with a case study. This is important, because the number of thunderstorms with extreme rainfall is increasing in Hungary. Orographic factors also contribute to the phenomena of flash flood formed by intense storms. Extreme precipitation may be one of the most dangerous causes of natural disasters. To avoid any damages, it is very important to make an accurate forecast as soon as possible enabling preparation and protection. The aim of the new method is to determine the chances of heavy rainfall, especially in critical regions, a few days in advance.

For a case study, we examined a flash flood event in Szilvásvárad, which occurred on June 10-11, 2018 (Tóth, 2020). On this day in Bánkút, which is the closest meteorological station to Szilvásvárad, $174 \mathrm{~mm} / 24$ hours precipitation was registered between 06 UTC, June 10, 2018 and 06 UTC, June 11, 2018 (OMSZ, 2018). The rainfall seemed to be a completely local problem in the Bükk area, because a few $\mathrm{km}$ away from Szilvásvárad, only $4 \mathrm{~mm} / 24$ hours precipitation was measured in Eger (OMSZ, 2018).

Even experimental ecPoint Rainfall GRIB files, containing 12 hours precipitation amount were available with 6 hourly frequency for us, but due to archiving limitations, only 00-12 UTC and 12-00 UTC GRIB files were archived in OMSZ. Currently, ecPoint Rainfall GRIB files are not available from ECMWF's MARS archive. ECMWF plans to provide 6 hours and 24 hours ecPoint Rainfall post-processed products in the future, but during our study, the 24 hours post-processed products could not be used for the usual synoptical period, covering from 06 UTC to 06 UTC interval.

In our study, we concentrated on the investigation of the capability of the ecPoint Rainfall products, so we made a 24 hours observed precipitation chart covering from 12 UTC to 12 UTC based on the high density precipitation observation network of the OMSZ. Even in this case we have definitely less observations, approximately 310 stations than the standard 06-06 UTC synoptical period, but we can easily see the geographical density of the observation network used for validation. In addition to above mention reasons, as major part of intensive precipitation occurred in the second part of June 10, 2018 and first part of June 11, 2018 we made a map containing 24 hours precipitation covering this interval (Fig. 10). This map shows that the highest value, $92 \mathrm{~mm} / 24$ hours was measured in Bükkszentlélek and $18 \mathrm{~mm} / 24$ hours was measured in Eger. 
precipitation: 12 UTC June 10, 2018 - 12 UTC June 11, 2018

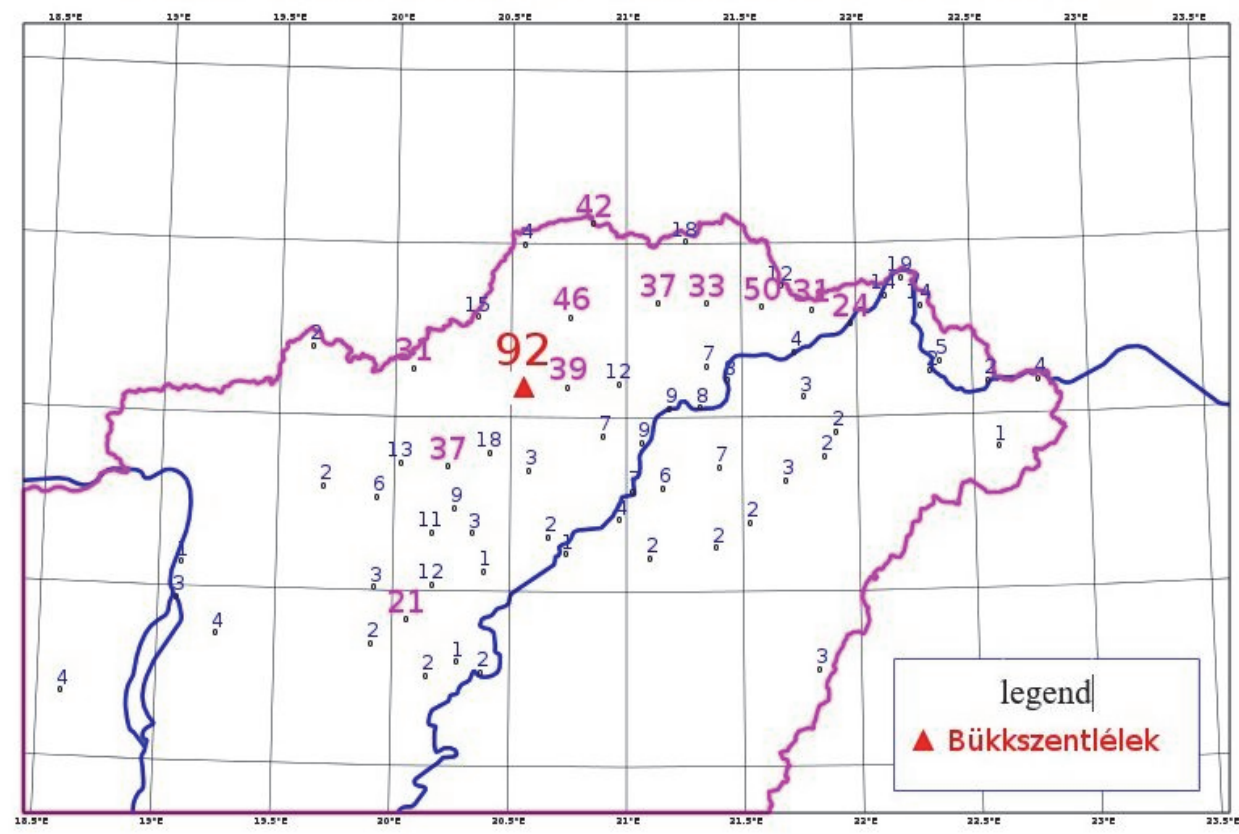

Fig. 10. Observed 24 hours precipitation between 12 UTC, 10 June, 2018 and 12 UTC, June 11, 2018.

In the north and southwest parts of Europe cyclones shaped the weather, while Central Europe was located in the warm sector. Over the Iberian and Balkan peninsulas, the high-altitude cold vortex emerged in those days had unstabilized the atmosphere, thus showers and thunderstorms interrupted the sunlight in many places. In Hungary, the formation of unstable atmospheric conditions was due to the shallow cyclone in southeast Europe, which gradually marched over the country. As a result, there was a strong cumulus cloud formation in the Northern Central Mountains in the afternoon, to which the lifting effect of the mountains significantly contributed. Due to the slow flow system, the rapidly developing thunderstorm cells did not move from the area for hours, which led to the accumulation of extreme rainfall.

The most intensive precipitation zone was reported from the Bükk area, where a total of $174 \mathrm{~mm} / 24$ hours of precipitation was measured. Such a large amount of precipitation is most characteristic of the monsoon regions, so it occurs rarely in Hungary, approximately every $10-20$ years. It is no accident that predicting these types of local, extreme amounts of precipitation zones is one of the biggest challenges for meteorologists, even with fine resolution of models. To alleviate this problem, ECMWF has developed the ecPoint Rainfall product, which has already estimated the rainstorm in June 2018 more accurately.

Figs. 11 and 12 display probability maps of ecPoint Rainfall in percentages: the accumulation of $10 \mathrm{~mm} / 12$ hours (Fig. 11) or more precipitation on one map and the accumulation of $30 \mathrm{~mm} / 12$ hours (Fig. 12) or 
more precipitation on the other. The forecasts were made on June 8 at 00 UTC for a period between +72 and +84 hours and on June 10 at 00 UTC for a period between +24 and +36 hours. Based on these maps, the expectation of higher rainfall in the Bükk is quite obvious. While precipitation was probable with different probability values in all of the north and northeast parts of Hungary on the map that uses the $10 \mathrm{~mm}$ threshold index, on the map of $30 \mathrm{~mm}$ threshold index the local precipitation zone is nicely outlined. Although these maps predict the expected extreme and local precipitations with relatively low possibility, this information is very important for forecasters mainly because of the convective season in the hilly regions.
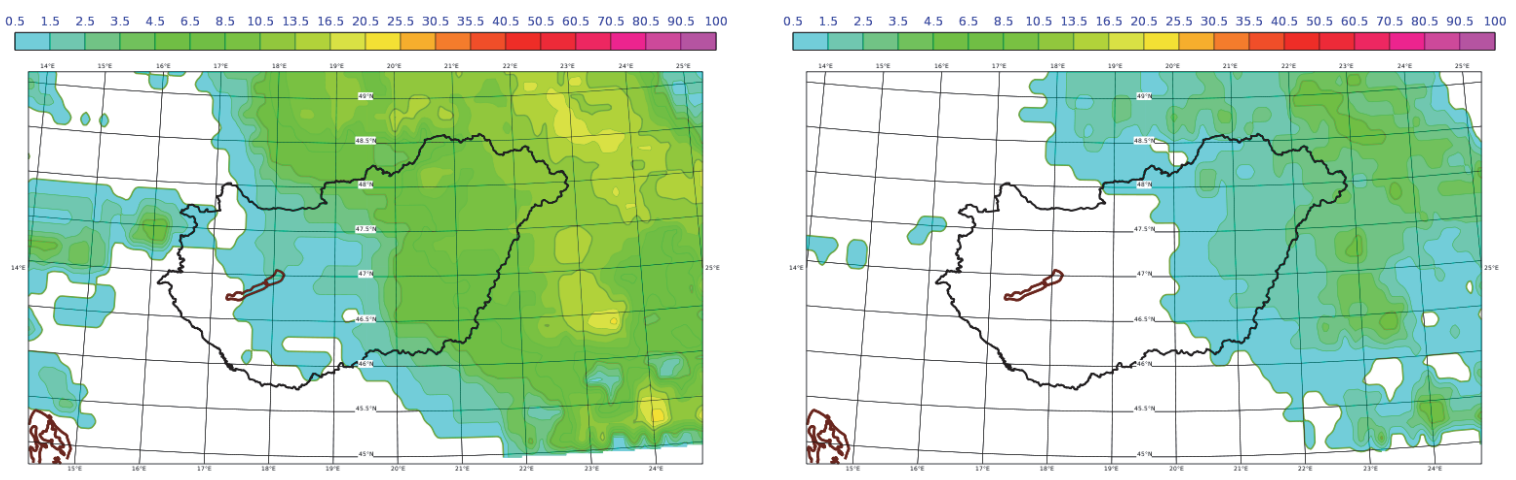

Fig. 11. Probability of precipitation exceeding $10 \mathrm{~mm} / 12$ hours (left) and $20 \mathrm{~mm} / 12$ hours (right). EcPoint Rainfall forecasts were made on June 8 at 00 UTC for a period between +72 and 84 hours.
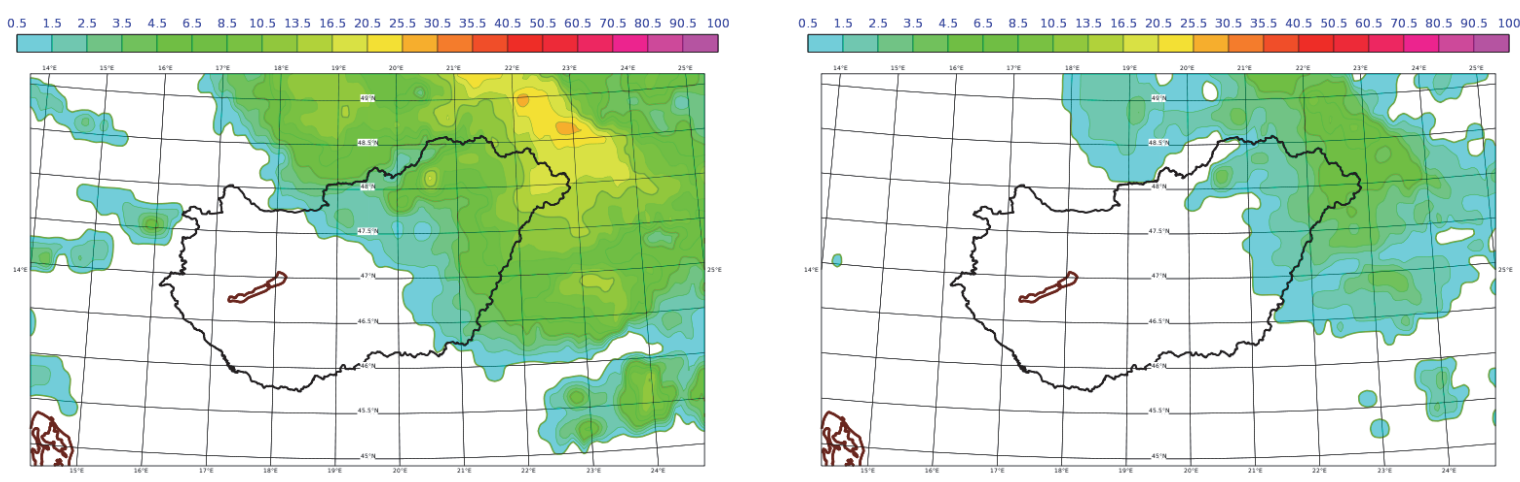

Fig. 12. Probability of precipitation exceeding $10 \mathrm{~mm} / 12 \mathrm{~h}$ (left) and $20 \mathrm{~mm} / 12$ hours (right). EcPoint Rainfall forecasts were made on June 10, at 00 UTC for a period between +24 and 36 hours. 
It is necessary to highlight that the new product was not available to the forecasters by this flash flood event. If in the summer of 2018 ecPoint Rainfall had been available, the forecasters could have identified the endangered areas 3 or 4 days earlier.

A new ensemble meteogram of ecPoint Rainfall predictors was created (Fig. 12) in order the forecasters get a comprehensive view of the weather situations and that the new product can be used properly. If synoptic meteorologists look at the ensemble meteogram, they will immediately see how the predictors used in the production of ecPoint Rainfall behave. Using the ensemble meteogram, they can conclude which predictors are crucial for the forecast of the ecPoint Rainfall; moreover, it contributes to decision-making of forecasters.

Fig. 13 shows the ensemble meteogram for the case study in Szilvásvárad. The diagram was divided to 4 parts, which are 4 variables. At the top, there is the 12 hours precipitation forecast of the ecPoint Rainfall and the ensemble in $\mathrm{mm}$. When the ecPoint Rainfall 12 hours values of that Sunday were summed, more than $70 \mathrm{~mm}$ precipitation was predicted, while the ensemble forecast expected much less. In the second part, there is a convective precipitation rate, which from Sunday afternoon gradually increased. Located under the convective precipitation rate is the $700 \mathrm{hPa}$ wind speed in $\mathrm{m} / \mathrm{s}$. Due to slow flow, the previously formed storm cells stood in one place, which caused a significant amount of precipitation. At the bottom of the figure there is the CAPE index in $\mathrm{J} / \mathrm{kg}$, which has grown constantly in the investigated period, and at 18 UTC the CAPE index was about $1500-2000 \mathrm{~J} / \mathrm{kg}$. Analyzing the meteogram, an extreme precipitation event could be expected, because the high CAPE index associated with the orographic buoyancy further increased the probability of flash flood events. In conclusion, the new ecPoint Rainfall product is a promising innovation for forecasting these events in advance.

In the case of June 10,2018, the main problem was the amount of water flowing down from the mountains. At dawn, Szilvásvárad was flooded with water, which caused huge damage to the persons and to the community as well. The new product developed by the ECMWF may prove to be a consequential tool for the early detection of such natural disasters, which is completely supported by this study. 
ecPoint Rainfall ensemble meteogram

10 june 201800 UTC Szilvasvarad

12 hour precipitation: ensemble / ecPoint Rainfall

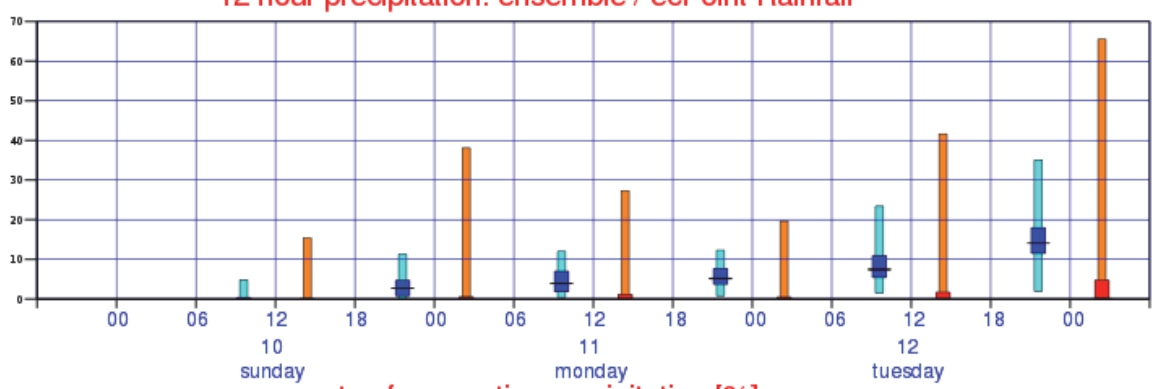

rate of convective precipitation [\%]

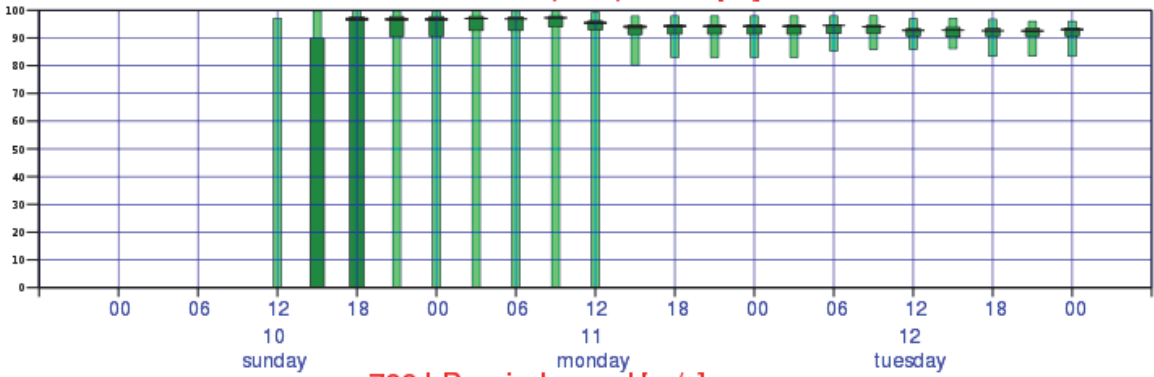

$700 \mathrm{hPa}$ wind speed $[\mathrm{m} / \mathrm{s}]$

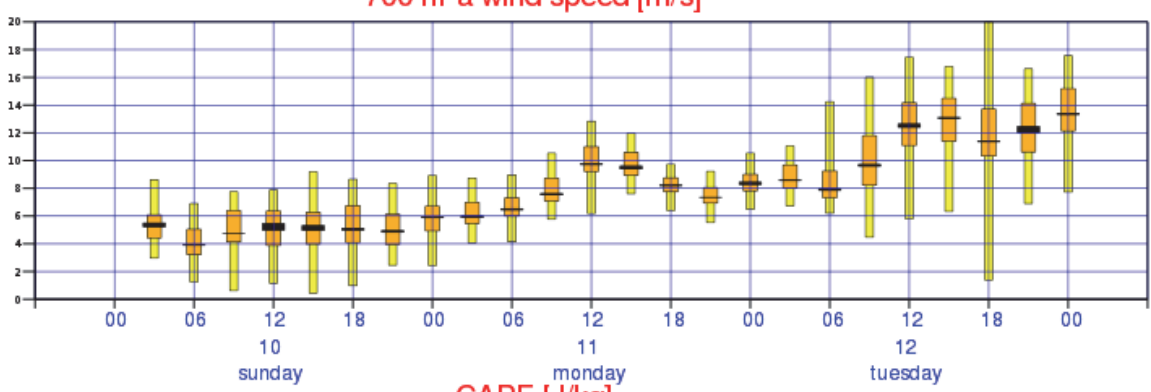

CAPE $[\mathrm{J} / \mathrm{kg}]$

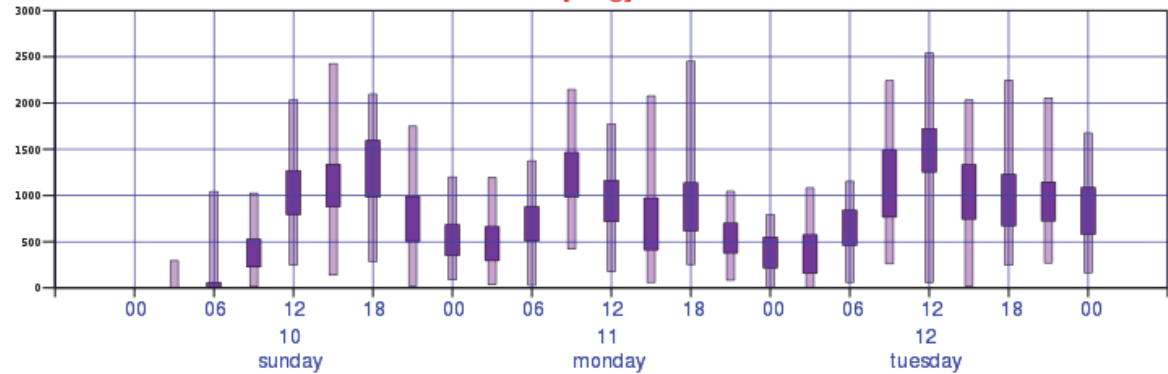

Fig. 13. Ensemble meteogram based on predictors of ecPoint Rainfall.

\section{Conclusion}

Accurate forecast of ecPoint of the precipitation amount is quite challenging even for modern numerical weather forecasting models. In our work, a comprehensive validation of a new innovative post-processing tool, the ECMWF's ecPoint Rainfall products was aimed. EcPoint Rainfall products can successfully provide information about the probability of subgrid scale precipitation, so extreme events, including flash floods can be warned in time. 
During our work, the capability of this method was studied by different verification methods, approximately 75 cases were selected from a very intensive convective period covering the summer of 2018. As a result of this work, ecPoint Rainfall products operationally support decision makers in the warning of the extreme precipitation events at OMSZ.

\section{References}

Bodolainé, J.E., 1983: Árhullámok szinoptikai feltételei a Duna és a Tisza vízgyüjtő területén. OMSZ Hivatalos Kiadványai 56, Budapest. (in Hungarian)

Bonta, I. and Újváry K., 2011: Hidrológiai célú mennyiségi csapadékelőrejelzés hazánkban. Magyar Tudomány 172, 1449-1458. (in Hungarian)

Bölöni, G., Kullmann, L., and Horányi, A., 2009: Use of ECMWF lateral boundary conditions and surface assimilation for operational ALADIN model in Hungary. ECMWF Newsletter 119, 29-35.

Forbes, R., Tsonevsky, I., Hewson, T., and Leutbecher, M., 2014: Towards predicting high-impact freezing rain events. ECMWF Newsletter 141, 15-21.

Gascon, E., Hewson, T., and Sahin, C., 2018: New meteogram and map ecCharts products for precipitation type probabilities. ECMWF Newsletter 154, 2-3.

Hewson, T., Pillosu, F., Bonet, A., Russell, I., Sahin, C., and Pappenberger, F., 2019: New point rainfall products in ecCharts. ECMWF Newsletter 159, 9.

Hewson, T. and Pillosu, F., 2021: A new low-cost technique improves weather forecasts across the world. Nature, Preprint at https://arxiv.org/abs/2003.14397

T. Hewson, T, and Pillosu, F. , 2021 : A new low-cost technique improves weather forecasts across the world. Commun. Earth Environ. 2, 132. https://www.nature.com/articles/s43247-021-00185-9

|Horányi, A., Ihász, I., and Radnóti, G., 1996: ARPEGE/ALADIN: A numerical weather prediction model for Central-Europe with the participation of the Hungarian Meteorologi.cal Service. Idöjárás 100, 277-300.

Horányi, A., Kertész, S., Kullmann, L, and Radnóti, G., 2006: The ARPEGE/ALADIN mesoscale numerical modelling system and its application at the Hungarian Meteorological Service., Időjárás 110, 203-227.

Horányi, A., Mile, M., and Szücs, M., 2011: Latest developments around the ALADIN operational short-range ensemble prediction system in Hungary. Tellus 63A, 642-651.

Ihász, I., 1992: Hogyan müködik az első operatív hazai numerikus előrejelző modell? Légkör 37, 12-36. (in Hungarian)

Ihász, I., 2004: Experiments of clustering for central European area especially in extreme weather situations. Proceedings of the Ninth ECMWF Workshop on Meteorological Operational Systems, Reading UK, 10-14 November 2003, 112-116.

Ihász. I., Üveges, Z., Mile, M., and Németh, Cs., 2010: Ensemble calibration of ECMWF's mediumrange forecasts. Időjárás 114, 275-286.

Ihász, I. and Tajti, D., 2011: Use of ECMWF's ensemble vertical profiles at the Hungarian Meteorological Service. ECMWF Newsletter, 129, 20-24.

Ihász, I., 2014: Az operatív numerikus modellezés kezdeti évei Magyarországon: A svéd modell alkalmazása. In (eds. Horányi, A. and Szépszó, G.) Dévényi Dezső emlékkötet. 63-69. (in Hungarian)

Ihász. I., Mátrai, A., Szintai, B., Szücs, M., and Bonta, I., 2018: Application of European numerical weather prediction models for hydrological purposes. Időjárás 122, 59-79. DOI:10.28974/idojaras.2018.1.5.

Ihász, I. and Modigliani, U., 2019: 25 years of the cooperation between the Hungarian Meteorological Service and ECMWF. ECMWF Newsletter, 160, 9-10.

Kaba, M., 1995: Csatlakozásunk a Középtávú Időjárási Elörejelzések Európai Központjához. Légkör 40, 34. (in Hungarian) 
Mátrai, A. and Ihász, I., 2017: Calibrating forecasts of heavy precipitation in river catchments. ECMWF Newsletter 152, 32-35.

Mile, M., Bölöni, G., Randriamampianina, R., Steib, R., and Kucukkaraca, E., 2015: Overview of mesoscale data assimilation developments at the Hungarian Meteorological Service. Idójárás 119, 213-237.

OMSZ, 2018: Mint a monszun - új napi csapadékrekord a Bükkben (VI. 10.). (in Hungarian) https://www.met.hu/omsz/OMSZ_hirek/index.php?id=2576\&m=2 (last access: 8 December 2020)

Owens, R.G. and Hewson, T.D., 2018: ECMWF Forecast User Guide. Reading. ECMWF. doi: $10.21957 / \mathrm{m} 1 \mathrm{cs} 7 \mathrm{~h}$.

Pillosu, F. and Hewson, T., 2017: New point-rainfall forecasts for flash flood prediction. ECMWF Newsletter 153, 2-3.

Szintai, B., Szücs, M., Randriamampianina, R., and Kullmann, L., 2015: Application of the AROME non-hydrostatic model at the Hungarian Meteorological Service: physical parameterizations and ensemble forecasting. Idöjárás 119, 241-265.

Szücs, M., Sepsi, P., and Simon, A.: 2016: Hungary's use of ECMWF ensemble boundary conditions. ECMWF Newsletter 148, 24-31.

Tóth, B., 2020: Kistérségü extrém csapadékmennyiség valószínüségének becslése ECMWF ensemble előrejelzések alapján. Master Thesis, Budapest. (in Hungarian)

Woods, A., 2005: Medium-Range Weather Prediction - The European Approach. Springer, 270 p. 